\title{
HYDROGEN PEROXIDE LEVELS CORRELATE WITH SUPEROXIDE DISMUTASE IN IRAQI WOMEN WITH PREGNANCY-INDUCED HYPERTENSION
}

\author{
SAJA MUHANAD BAYRAM ${ }^{1,2 *}$, LINA A SALIH ${ }^{2}$, SAMIA A ELEIWE ${ }^{3}$ \\ ${ }^{1}$ Department of Medical Laboratory Techniques, Al-Esraa University College, Baghdad, Iraq. ${ }^{2}$ Department of Biology, College of \\ Science, University of Baghdad, Baghdad, Iraq. ${ }^{3}$ Department of Histology, Anatomy, and Embryology, College of Medicine University of \\ Mustansiriyah, Baghdad, Iraq. Email: saja.bayram@email.com \\ Received: 20 July 2018, Revised and Accepted: 17 September 2018
}

ABSTRACT

Objective: Pregnancy-induced hypertension (PIH) is a major pregnancy complication that leads to maternal mortality. Here, we have scrutinized the correlation between serum levels of hydrogen peroxide $\left(\mathrm{H}_{2} \mathrm{O}_{2}\right)$ and superoxide dismutase (SOD) in PIH.

Methods: Serum samples were collected from 80 Iraqi women ( 40 women with PIH as patients group, 20 normotensive pregnant women as a positive control, and 20 normotensive non-pregnant women as a negative control) all groups were diagnosed clinically.

Results: Serum of $\mathrm{H}_{2} \mathrm{O}_{2}$ and SOD levels was measured for all studied groups. Results showed that there were no significant variances in age and gestational age distribution between all studied groups. Furthermore, result showed that the serum level of SOD was a highly significant decrease in PIH in compared to control groups while $\mathrm{H}_{2} \mathrm{O}_{2}$ was a highly significant increase in PIH in compared with control groups. The obtained results also indicated that there was a negative correlation between SOD and $\mathrm{H}_{2} \mathrm{O}_{2} \mathrm{PIH}$ women while no correlation in other control groups.

Conclusion: Our study showed that there was a correlation between $\mathrm{H}_{2} \mathrm{O}_{2}$ levels and SOD in PIH. These imbalance lead to generate oxidative stress that could be responsible for starting and progression of pathological processes related to PIH and may be a critical determinant of diseases. Testing for SOD and $\mathrm{H}_{2} \mathrm{O}_{2}$ level can be a monitoring instrument for oxidative stress in early pregnancy, and they could help in the detection and consequently prevent future hypertension in pregnancy.

Keywords: Pregnancy-induced hypertension, Oxidative stress, Superoxide dismutase, Hydrogen peroxide, Iraq, Baghdad.

(c) 2018 The Authors. Published by Innovare Academic Sciences Pvt Ltd. This is an open access article under the CC BY license (http://creativecommons. org/licenses/by/4. 0/) DOI: http://dx.doi.org/10.22159/ajpcr.2019.v11i11.28632

\section{INTRODUCTION}

One of the main causes of maternal mortality was hypertension [1]. The elevated or uncontrolled blood pressure (BP) leads to early and cesarean delivery also caused various complications to both mother and fetus [2]. Pregnancy-induced hypertension (PIH) is the elevated in a systolic BP level of $\geq 140 \mathrm{mmHg}$ and/or diastolic BP (DBP) level of $\geq 90 \mathrm{mmHg}$. PIH is one of the primary causes of death for pregnant mothers [3]. The onset of disease typically occurs at 20 weeks gestation [4]. Multiple organs dysfunction can occur, which may be a risking factor for mother and fetus life. The placenta is important organ to support normal pregnancy because it becomes a connection between mother and fetus. The placenta was developed since 8-18 weeks of gestation act as modified connecting channel and dilated also unresponsive to vasoconstrictors [4]. In preeclampsia, placentation was proceed incompletely caused BP increased and had low perfusion. Imbalance between circulate angiogenesis factors and maternal response will determine the clinical symptoms [1].

Oxidative stress is a central pathogenic in PIH [5]. Oxidative stress defined as an imbalance between the cellular generation of reactive oxygen species (ROS) and the capacity of antioxidants to prevent oxidative damage, oxidative stress has been implicated in a wide variety of disease and degenerative states including: Cancer, rheumatoid arthritis, cardiovascular disease, aging, and most importantly for this investigation preeclampsia [6]. Various kinds of stress during pregnancy are often inevitable. Such events can cause an elevation in the level of oxidative markers, thus activating the extension of the cellular antioxidative complex [7].

Superoxide dismutase (SOD) is an antioxidant enzyme that maintenances and reduces of cells damage that caused by superoxide free radical, which is the most common in the body. SOD catalyzes the dismutation of superoxide radicals to hydrogen peroxide $\left(\mathrm{H}_{2} \mathrm{O}_{2}\right)$ and molecular oxygen. Under pathological and physiological conditions, SOD acts as the first line from oxidative stress protection [8].

$\mathrm{H}_{2} \mathrm{O}_{2}$ is made by stimulation of numerous receptors on the cell surface and works as an intracellular messenger in many physiological events regulation [9]. The potential for conversion of $\mathrm{H}_{2} \mathrm{O}_{2}$ to more reactive species is controlled inside the cells, first, by systems that control the obtainability of metals such as iron and, second, by the action of many metabolizing enzymes for $\mathrm{H}_{2} \mathrm{O}_{2}$. If not controlled, the reaction of transition metals with $\mathrm{H}_{2} \mathrm{O}_{2}$ can cause cells oxidative stress [10]. $\mathrm{H}_{2} \mathrm{O}_{2}$, superoxide radical, is mainly responsible for the auto-oxidation of many biological components during the metabolism of the cell [11]. This study is one of the first trials at all of Iraq that aim is to determine the correlation between $\mathrm{H}_{2} \mathrm{O}_{2}$ and SOD as an oxidative stress marker in Iraqi women with $\mathrm{PIH}$ in compression to normotensive pregnant and non-pregnant woman.

\section{MATERIALS AND METHODS}

\section{Participant}

A total of 80 participant women involved in this study during their attendance at Fatima Al-Zahraa Hospital, Baghdad, Iraq, through the period from October 2017 to January 2018. Women were selected as follows: 40 women with PIH as a patient group, 20 normal pregnant women as a positive control, and 20 non-pregnant women as a negative control.

\section{Demographic parameter}

A questionnaire form included for all studied groups and contains age and gestational age. 
Sample collection

Five milliliters of venous blood has been collected from PIH, normotensive pregnant, and non-pregnant women using a clean plain tube and allowable to clot at $37^{\circ} \mathrm{C}$ for $10 \mathrm{~min}$. Then, it has been centrifuged for $5 \mathrm{~min}$ at $2500 \mathrm{rpm}$ until the serum separated. Serum was reserved at $-20^{\circ} \mathrm{C}$ until used.

\section{SOD and $\mathrm{H}_{2} \mathrm{O}_{2}$ levels determination in serum}

Superoxide Dismutase (SOD) catalyse the dismutation of the superoxide radical $\left(\mathrm{O}_{2}^{-}\right)$into hydrogen peroxide $\left(\mathrm{H}_{2} \mathrm{O}_{2}\right)$ and elemental oxygen $\left(\mathrm{O}_{2}\right)$. Test principle based on ions generated from the conversion of xanthine to uric acid, and hydrogen peroxide by xanthine oxidase (XOD), convert NBT to NBT-diformazan. NBT-diformazan absorbs light at $560 \mathrm{~nm}$. By using a Colorimetric method microplate assay kit according to the manufacturer's instructions (Cohesion Biosciences, UK).While hydrogen Peroxide $\left(\mathrm{H}_{2} \mathrm{O}_{2}\right)$ is a reactive oxygen metabolic product that serves as a key regulator for a number of oxidative stress-related states. $\mathrm{H}_{2} \mathrm{O}_{2}$ react with titanium sulfate, the products can be measured at a colorimetric readout at $415 \mathrm{~nm}$ according to the manufacturer's instructions (Cohesion Biosciences, UK). $\mathrm{H}_{2} \mathrm{O}_{2}$ and SOD were determined in women with PIH in addition to normotensive pregnant and nonpregnant women.

\section{Statistical analysis}

The Statistical Analysis System (SAS, 2012) program was used to effect of different factors in study parameters. The minimum significant difference LSD test (ANOVA) was used to significant compare between means of obtained results. Also it was Estimated of the correlation coefficient between different parameters in this study (SAS, 2012).

\section{RESULTS}

The analysis of data showed that there were no significant variances $(p<0.01)$ by means of age and gestational age distribution between all studied groups. The mean of ages was $(27.82 \pm 1.01,27.75 \pm 1.55$, and $27.85 \pm 2.08$ ) in PIH, positive control and negative control, respectively, while gestational age means were $27.47 \pm 1.74$ and $26.90 \pm 1.11$ for PIH and positive control, respectively (Table 1 ).

The concentration of serum $\mathrm{H}_{2} \mathrm{O}_{2}$ was significantly higher in the PIH group compared to the control groups $(1.467 \pm 0.03,0.736 \pm 0.03$, and $0.659 \pm 0.06$ ). On the other hand, SOD level was significantly low in $\mathrm{PIH}$ the mean $\pm \mathrm{SD}$ was $1.393 \pm 0.04$ in comparison with control positive group which was $2.194 \pm 0.03$ and $3.027 \pm 0.13$ in control negative (Table 2 and Fig. 1).

The data analysis showed that there was a negative correlation between SOD and $\mathrm{H}_{2} \mathrm{O}_{2}$ in PIH women ( $\left.\mathrm{r}=-0.74\right)$, while there was no correlation between the positive and negative control group $(-0.14$ and -0.04$)$, respectively (Table 3).

\section{DISCUSSION}

$\mathrm{H}_{2} \mathrm{O}_{2}$ was significantly higher in PIH in comparison with control groups. The obtained result agreed with others studies in which they explained that placental oxidative stress can be identified by increased of serum concentrations of ROS such as $\mathrm{H}_{2} \mathrm{O}_{2}[12,13]$. In preeclampsia, the increased of circulating vasoconstrictor $\mathrm{H}_{2} \mathrm{O}_{2}$ levels have been distinguished and may be a reason for the vasoconstriction and hypertension present in the disease [14].

The increase of ROS including $\mathrm{H}_{2} \mathrm{O}_{2}$ was indicating the prevalence of enhanced oxidative stress that could have caused toxicity linked to antioxidants and apoptosis thus can cause miscarriage [15].

Our result also showed decreases in the level of SOD in PIH in comparison with control groups. Superoxide dismutase activity was found to be decreased with a consequent increase of the superoxide anion in the undernourished offspring, which also signposts that the formation of $\mathrm{H} 2 \mathrm{O} 2$ decreased. Subsequent the reduction in levels of
Table 1: Demographical parameter in all studied groups

\begin{tabular}{lll}
\hline \multirow{2}{*}{ Group } & Mean \pm SE \\
\cline { 2 - 3 } & Age (year) & Gestation age (week) \\
\hline PIH & $27.82 \pm 1.01^{\mathrm{a}}$ & $27.47 \pm 1.74^{\mathrm{a}}$ \\
Positive control & $27.75 \pm 1.55^{\mathrm{a}}$ & $26.90 \pm 1.11^{\mathrm{a}}$ \\
Negative control & $27.85 \pm 2.08^{\mathrm{a}}$ & - \\
LSD value & $4.234 \mathrm{NS}$ & $5.208 \mathrm{NS}$ \\
$\mathrm{p}$ & 0.999 & 0.825 \\
\hline
\end{tabular}

** $(\mathrm{p}<0.01)$, NS: Non-significant. Means having with the different letters in the same column differed significantly. PIH: Pregnancy-induced hypertension, SE: Standard error

Table 2: $\mathrm{H}_{2} \mathrm{O}_{2}$ and SOD concentration in different studied groups

\begin{tabular}{lll}
\hline \multirow{2}{*}{ Group } & \multicolumn{2}{l}{ Mean \pm SE } \\
\cline { 2 - 3 } & $\mathbf{H}_{2} \mathbf{O}_{2} \mathbf{( U / m g )}$ & SOD $(\mathbf{U} / \mathbf{m g})$ \\
\hline PIH & $1.467 \pm 0.03^{\mathrm{a}}$ & $1.393 \pm 0.04^{\mathrm{c}}$ \\
Positive control & $0.736 \pm 0.03^{\mathrm{b}}$ & $2.194 \pm 0.03^{\mathrm{b}}$ \\
Negative control & $0.659 \pm 0.06^{\mathrm{b}}$ & $3.027 \pm 0.13^{\mathrm{a}}$ \\
LSD value & $0.126^{* *}$ & $0.209^{* *}$ \\
$\mathrm{p}$ & 0.0001 & 0.0001 \\
\hline
\end{tabular}

** $(\mathrm{p}<0.01)$. Means having with the different letters in the same column differed significantly. $\mathrm{H}_{2} \mathrm{O}_{2}$ : Hydrogen peroxide, SOD: Superoxide dismutase, PIH: Pregnancy-induced hypertension, SE: Standard error

Table 3: Correlation coefficient between SOD and $\mathrm{H}_{2} \mathrm{O}_{2}$ in all studied groups

\begin{tabular}{llllll}
\hline Parameters & & $\mathrm{H}_{2} \mathbf{O}_{2}$ & & & \\
\cline { 1 - 1 } \cline { 5 - 6 } SOD & Groups & PIH & $\begin{array}{l}\text { Positive } \\
\text { control }\end{array}$ & $\begin{array}{l}\text { Negative } \\
\text { control }\end{array}$ \\
\hline & $\mathrm{r}$ & $-0.74^{* *}$ & $-0.14 \mathrm{NS}$ & $-0.04 \mathrm{NS}$ \\
\hline
\end{tabular}

${ }^{*}(\mathrm{p}<0.05),{ }^{* *}(\mathrm{p}<0.01), \mathrm{NS}$ : Non-significant. $\mathrm{H}_{2} \mathrm{O}_{2}$ : Hydrogen peroxide

SOD: Superoxide dismutase, PIH: Pregnancy-induced hypertension

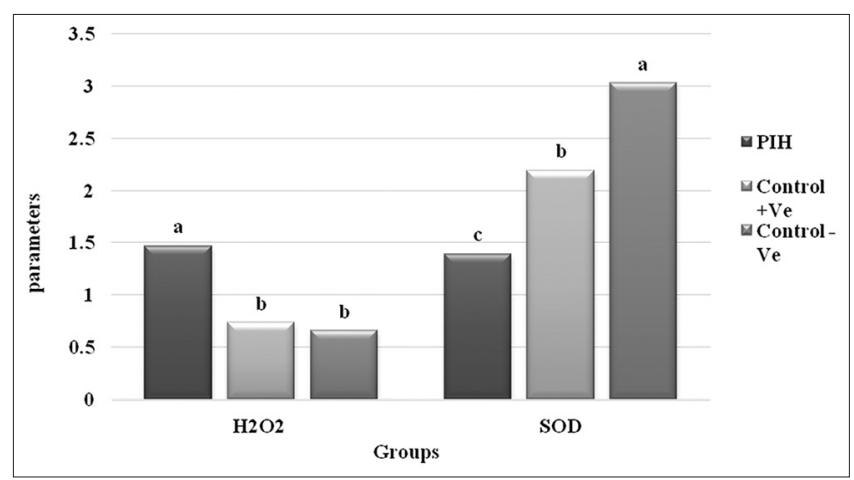

Fig. 1: Hydrogen peroxide and superoxide dismutase concentration in all studied groups

SOD in plasma that act as an antioxidant defense against oxidative stress in preeclampsia [16].

The probable reason for SOD activity decrease in preeclampticwomen may be due to improved free radicals activity which leads to SOD production decreasing [17]. Ilhan et al. found significantly decreased in SOD for women with preeclampsia compared to normotensive non-pregnant and pregnant women [18]. Mahadik and Sina were proved that the level of SOD was significantly decreased with the increments in DBP. This may indicate participation of free radicals in preeclampsia pathophysiology. It was concluded that low serum SOD levels are important in deciding the time of intervention as termination of pregnancy [19]. 
SOD is a catalyzes enzyme that acts on superoxide $\left(\mathrm{O}_{2}^{-}\right)$radical dismutation into either ordinary molecular oxygen $\left(\mathrm{O}_{2}\right)$ or $\mathrm{H}_{2} \mathrm{O}_{2}$ [20]. Under normal conditions, the cells use their antioxidant defenses, which convert $\mathrm{H}_{2} \mathrm{O}_{2}$ to oxygen and water, thereby keeping the manufacture of the ROS system under control. Increased $\mathrm{H}_{2} \mathrm{O}_{2}$ can result from overproduction of ROS, accelerated lipid peroxidation, and/or decreased antioxidant capacity. $\mathrm{H}_{2} \mathrm{O}_{2}$ can use as an indicator of oxidative stress [12].

Oxidative stress takes place when the manufacture of ROS $\left(\mathrm{H}_{2} \mathrm{O}_{2}\right)$ overwhelms the antioxidant capacity (SOD) resulting in overall damage to cells and has been implicated in PIH pathology [21]. One of the most central defense mechanisms of antioxidant is SOD, and its lower action was used in the determination of low antioxidant status and was even predictive of PIH development [22].

\section{CONCLUSION}

Our study shows, for the $1^{\text {st }}$ time in the best of our knowledge, that there is a correlation between $\mathrm{H}_{2} \mathrm{O}_{2}$ levels and SOD in PIH. These imbalance lead to generate oxidative stress that could be able in starting and progression of pathological processes related to PIH and may be a critical determinant of diseases. Concentration level testing for SOD and $\mathrm{H}_{2} \mathrm{O}_{2}$ can be a monitoring instrument for oxidative stress in early pregnancy, and they could help in the detection and consequently prevent future hypertension in pregnancy.

\section{ACKNOWLEDGMENT}

I would like to introduce my thanks for the patient for their agreement and contribution in successfully of this study.

\section{AUTHORS CONTRIBUTION}

Author Saja Muhanad Bayram contributed to the design and implementation of the research, sample collection from studied group and then to the analysis of the results and write the manuscript. Author Lina A. Salih supervised the project, study designed, give final approval of the version to be submitted. Author Samia A Eleiwe help in collection and diagnosis of disease in the patient group. Furthermore, we have to say that all authors discussed the results and contributed to the final manuscript.

\section{CONFLICTS OF INTEREST.}

None.

\section{REFERENCES}

1. Prijanti AR, Marissa N, Paramita R, Humaira S, Nisa E. Analysis of oxidative stress markers malondialdehyde, glutathione, nitric oxide, and prorenin level in preeclampsia placental tissues. Asian J Pharm Clin Res;2018:4.

2. Velusamy S. Comparison of treatment outcome of antihypertensive drugs in the management of pregnancy induced hypertension. Int $\mathrm{J}$ Pharm Pharm Sci;2017:3.

3. Pennings JL, Kuc S, Rodenburg W, Koster MP, Schielen PC, de Vries A, et al. Integrative data mining to identify novel candidate serum biomarkers for pre-eclampsia screening. Prenat Diagn 2011;31:1153-9.

4. Kintiraki E, Papakatsika S, Kotronis G, Goulis DG, Kotsis V. Pregnancy-induced hypertension. Hormones (Athens) 2015;14:211-23.

5. Rubattu S, Pagliaro B, Pierelli G, Santolamazza C, Castro SD, Mennuni S, et al. Pathogenesis of target organ damage in hypertension: Role of mitochondrial oxidative stress. Int J Mol Sci 2014;16:823-39.

6. Kavitha V, Srinivas B, Kumar MV, Shashikanth P. Assessment of placental oxidative stress parameters in preeclamptic and normal pregnant women. Asian J Pharm Clin Res 2016;9:105-9.

7. Bernhardt LK, Bairy LK, Madhyastha S. N-Acetylcysteine reverses late gestational stress induced maternal oxidative damage. Int J Pharm Pharm Sci 2015;7:165-8.

8. Matsuda S, Nakagawa Y, Tsuji A, Kitagishi Y, Nakanishi A, Murai T, et al. Implications of PI3K/AKT/PTEN signaling on superoxide dismutases expression and in the pathogenesis of Alzheimer's Disease. Diseases 2018;6:28.

9. Rhee SG, Woo HA, Kang D. The role of peroxiredoxins in the transduction of $\mathrm{H}_{2} \mathrm{O}_{2}$ signals. Antioxid Redox Signaling 2018;28:537-57.

10. Franchina DG, Dostert C, Brenner D. Reactive oxygen species: Involvement in $\mathrm{T}$ cell signaling and metabolism. Trends Immunol 2018;39:489-502.

11. Vishnuvathan VJ, Lakshmi KS, Srividya AR. Study of antioxidant activity of formononetin by in vitro method. Int J Pharm Pharm Sci 2017;9:273-8.

12. Kharfi A, Giguère Y, De Grandpré P, Moutquin JM, Forest JC. Human chorionic gonadotropin (hCG) may be a marker of systemic oxidative stress in normotensive and preeclamptic term pregnancies. Clin Biochem 2005;38:717-21.

13. Aris A, Benali S, Ouellet A, Moutquin JM, Leblanc S. Potential biomarkers of preeclampsia: Inverse correlation between hydrogen peroxide and nitric oxide early in maternal circulation and at term in placenta of women with preeclampsia. Placenta 2009;30:342-7.

14. Agarwal A, Aponte-Mellado A, Premkumar BJ, Shaman A, Gupta S. The effects of oxidative stress on female reproduction: A review. Reprod Biol Endocrinol 2012;10:49

15. Ghneim HK, Alshebly MM. Biochemical markers of oxidative stress in Saudi women with recurrent miscarriage. J Korean Med Sci 2016;31:98-105.

16. Khatri M. Circulating biomarkers of oxidative stress in normal pregnancy and preeclampsia and efficacy of antioxidant supplementation. Int $\mathrm{J}$ Reprod Contracept Obstet Gynecol 2016;2:304-10.

17. Bargale AB, Ganu JV, Trivedi DJ, Mudaraddi R, Kamble PS. Serum superoxide dismutase and paraoxonase-1 activity in preeclamptic patients. Int J Pharm Bio Sci 2011;2:705-9.

18. Ilhan N, Ilhan N, Simsek $M$. The changes of trace elements, malondialdehyde levels and superoxide dismutase activities in pregnancy with or without preeclampsia. Clin Biochem 2002;35:393-7.

19. Mahadik KV, Sina SA. Study of serum levels of superoxide dismutase in preeclampsia and eclampsia: Role of the test as a predictive tool. J Obstet Gynaecol Res 2003;29:262-7.

20. Hayyan M, Hashim MA, Al Nashef IM. Superoxide ion: Generation and chemical implications. Chem Rev 2016;116:3029-85.

21. Burton GJ, Jauniaux E. Oxidative stress. Best Pract Res Clin Obstet Gynaecol 2011;25:287-99.

22. Pennings JL, Imholz S, Zutt I, Koster MP, Jacqueline E. Predictive performance of a seven-plex antibody array in prenatal screening for down syndrome. Dis Markers 2015;2015:519851. 